Sclero-corneal trephining continues to hold its place as the routine operation for glaucoma, but a trial of iris inclusion was made on a few patients whose other eye had been successfully trephined.

Reference is made to the comparatively rare occurrence of sympathetic ophthalmitis in the East. This rarity must be familiar to most ophthalmic surgeons of wide Eastern experience. A record has been kept of those patients who might reasonably be expected to contract the disease; and 62 such have been noted since 1921. But not a single one has so far reported any trouble.

Notes and illustrations, contributed by other members of the staff, of many interesting and rare cases are included in the report.

\title{
CORRESPONDENCE
}

\section{PHYSICIAN, SURGEON, SPECIALIST}

To the Editor of The British Journal of Ophthalmology

SIR,-As the above title may seem somewhat cryptic I lose no time in stating that it has been suggested by two articles in the Lancet of October 17 and October 24, 1925. Although these two articles have no connection one with the other they seem to bear upon the same point, namely, the mutual interdependence of the various branches of medicine and surgery. The first article (October 1 1), by Bishop Harman, "Hospitals, General and Special," constitutes the Appendix to the Sixth Annual Report of the Voluntary Hospitals in Great Britain (excluding London). The second (October 24) is by P. Watson-Williams, "Anatomically Irregular Sphenoidal Sinusitis with Optic Neuritis."

Harman says: "The determination of the relative value of special and general hospitals must be based upon their working efficiency in regard to the patient. Which type of hospital is best for the patient, whatever be the nature of his ailment; and which in the long run fosters the best type of medical practitioner, that is to say, the practitioner most able to cope with the disability of the patient. . . . In my judgment there can be no doubt that the general hospital is better than the special hospital, better for the patient, and better in that it cultivates a superior type of medical work." Considerations of space prohibit the full statement of Harman's argument. It is temperately developed and makes all due allowance in favour of the special hospital under certain circumstances, but, nevertheless, is strongly in favour of the general hospital with special departments, so that the patient may 
get the full benefit of all the departments if necessary. In this connection it is pointed out very truly that the necessity for a specialist to be in touch with all medicine and surgery is shown by the appointment of specialists in other departments on the staffs of special hospitals. It is possible, indeed it is extremely likely, that there will not be agreement in all quarters with Harman's point of view and that there will be many enthusiasts holding the opposite opinion. That there is much to be said for the general as against the special hospital is well illustrated by WatsonWilliams' two cases. Here the patients' safety depended upon the highest degree of skill on the part of a nasal surgeon. These two patients each suffered from sphenoidal sinus disease with which eye symptoms were associated. In the one case the left sphenoidal sinus was large and healthy and easily reached through either nasal passage, the right sinus small and highly infected. In the other case a large right sinus was infected while the small left one was healthy. The difficulty of diagnosis in such cases of irregularity of the sinuses is obvious, and it illustrates the advantage of having everything, so to speak, under one roof in rather an emphatic way. Do you think, Sir, that the readers of this journal might be invited to express their opinions in the correspondence column?

Yours truly,

ERnest Thomson.

Stirling.

\section{OPHTHALMIC FOLK-LORE}

To the Editor of The British Journal of Ophthalmology SIR,-In view of your annotation on ophthalmic folk-lore (Brit. Jl. of Ophthal., Vol. IX, pp. 638-9), the following extracts from a little-known book may interest your readers.

These extracts are translated from "Meddygon Myddfeu,"(a) the Welsh medical work said to have been composed in the 13th century by Rhiwallon, medical attendant to Rhys Gryg, lord of Llandovery and Dinefwr.

1. "A recent blow or a recent wound on the head. The sooner it is dressed the better lest blood should come on to the dura mater and coagulate there. From the time of raising the bone from the dura mater take violet and fresh butter and rub them together. If no violet is available take white of egg, and linseed, and rub them together, and place them to the wound, and then make an ointment of herbs and butter and tallow, and place them to it till it is healed. For that work of mercy the debt to the physician is a pound without food, or a hundred and eighty pence with food." 